\title{
Relationship Between Water Birds' Number and the Temperature in Beijing Wetland: A Case Study on Cuihu Wetland
}

\author{
Rujin Yu \\ Experimental High School Affiliated to Beijing Normal University, Beijing, 100032, China
}

\begin{abstract}
Beijing is an important transfer station of bird migration, and its function as a bird habitat is very significant. Wetland birds have an extremely high reference value as ecological indicators and are greatly affected by climate change. This study takes waterbirds in Beijing Cuihu Wetland Park as the research object, carries out a statistical analysis of the number of birds in each year, and summarizes the relationship between them and Beijing's climate change. The results showed that Anatidae and Ardeidae accounted for a substantial part of wetland waterfowl, and their number was increasing year by year. There was a significant correlation between the monthly average number of two kinds of waterfowls and the average monthly temperature, and the negative correlation was found between the number of Anatidae and the average monthly temperature. The number of Anatidae and Ardeidae in spring and autumn are related to the monthly average temperature, seasonal average temperature and annual average temperature of the previous year.
\end{abstract}

\section{Introduction}

Beijing, the capital of China, is located in the East Asian-Australasian Flyway (EAAF) among the eight major flyways. As one of the main habitats and flyways of migratory birds in north China, the research on ecological environment and bird protection in Beijing is particularly important [1]. Beijing Cuihu wetland, as an important urban park in Beijing, is a key part of the urban habitat in Beijing. It plays an important role in bird habitat. The diversity of plant habitats in Cuihu wetland has attracted a lot of birds because of the limited tourist flow and wetland ecosystem. Wetland has always been known as the "kidney of the earth", being a natural complex formed by the interaction of land and water, and also one of the most important ecological landscapes and human living environment in nature. It plays an important role in regulating and storing flood, purifying water quality, regulating climate, maintaining biodiversity and regional ecological security [2]. Its change is closely related to human survival, so it is particularly important to monitor and evaluate wetland ecosystem.

Climate warming has always been the focus of global scientific research. The temperature in the Northern Hemisphere has increased significantly in the past few decades [3]. A lot of evidence proved that the phenology and ecology of the population, species distribution and community composition are consistently showing symptoms of being affected by climate change. Climate change has brought extensive and far-reaching impacts on organisms [4]. Birds are one of the most active and eye-catching components of the ecosystem which are very sensitive to the changes of climate and environment. For example, migratory birds will choose to arrive at the migration site and breed ahead of time due to climate change [5]. Therefore, birds can be used as an objective indicator for monitoring global environmental change [6].

Birds, especially waterbirds, are the unique Higher biology and main top consumers in wetland ecosystem. The distribution, quantity, reproduction and physiological characteristics of waterfowl will respond to all kinds of disturbances suffered by wetlands. Therefore, birds can be used as indicators of wetland ecosystem monitoring and evaluation, which can be used as indicator organisms from wetland vegetation, wetland water environment, wetland biodiversity, wetland pollution, wetland ecosystem monitoring and evaluation. Because the trophic level of birds is closer to that of humans, birds as indicator organisms also have reference value for environmental risks faced by human beings [ 7 , 8].

There is previous research conducted to understand bird biodiversity in different parts of Beijing and analyses of the relations between community structure of birds and diversity of arthropods as well as vegetation structure and other studies on species diversity and seasonal changes. However, the relationship between birds' number and temperature in Beijing is not studied. Taking Beijing Cuihu wetland as a starting point, this paper discusses the correlation between the change of water bird population and the average temperature in recent years, putting forward some suggestions.

Vivian.wang@cas-harbour.org 


\section{Overview of research site}

For migratory birds, Beijing is an important energy supply station on the way to migration. As an important wetland park in Beijing, Cuihu wetland has played a great role in providing habitat for birds and maintaining natural ecological balance. Beijing Cuihu wetland is more than 30 kilometers away from the centre of Beijing. Its geographical coordinates are $40^{\circ} 5^{\prime} 47.41^{\prime \prime} \sim 40^{\circ} 5^{\prime} 51.16^{\prime \prime} \mathrm{N}, \quad 116^{\circ} 10^{\prime} 34.30^{\prime \prime}$ $116^{\circ} 10^{\prime} 41.43^{\prime \prime} \mathrm{E}$, with an altitude of $55.0 \mathrm{~m}$. The water area of Cuihu Wetland is nearly $700 \mathrm{hm} 2$, and the water source mainly comes from natural precipitation and artificial water diversion from Shangzhuang reservoir [9].

The area where Cuihu wetland is located belongs to temperate humid monsoon climate zone. It is cold and dry in winter with mostly northwest wind and is hot and rainy in summer, prevailing southeast wind. The annual average temperature is $12.5^{\circ} \mathrm{C}$, the average temperature in January is $-4.4^{\circ} \mathrm{C}$, the extreme minimum temperature is $-21.7^{\circ} \mathrm{C}$, the average temperature in July is $25.8^{\circ} \mathrm{C}$, and the maximum temperature is $41.6^{\circ} \mathrm{C}$. The annual sunshine time is 2662 hours, and the frost-free period is 211 days. The average annual precipitation is $628.9 \mathrm{~mm}$, which is concentrated in June to August in summer. The precipitation is $465.1 \mathrm{~mm}$, accounting for $70 \%$ of the annual precipitation. The precipitation from December to February in winter is the least, accounting for only $1 \%$ [10].

There are 87 species of wetland birds, accounting for $40 \%$ of the total birds, $15.6 \%$ and $49.7 \%$ of the wetland birds in China and Beijing respectively [12]. Among them, there are 7 species of birds under the national firstclass key protection, 31 species of birds under the national second-class key protection, and 14 species of birds under first-class key protection in Beijing, and 85 species of birds under second-class key protection in Beijing. There are herons, egrets, wild geese, pond herons, white swans, little bunnies, green headed ducks and other waterfowls in the Cuihu wetland, and then the animals under national second-class protection, such as black swan, pelican, yellow billed Huan, crown crane and other wild goose and duck water birds were introduced [13].

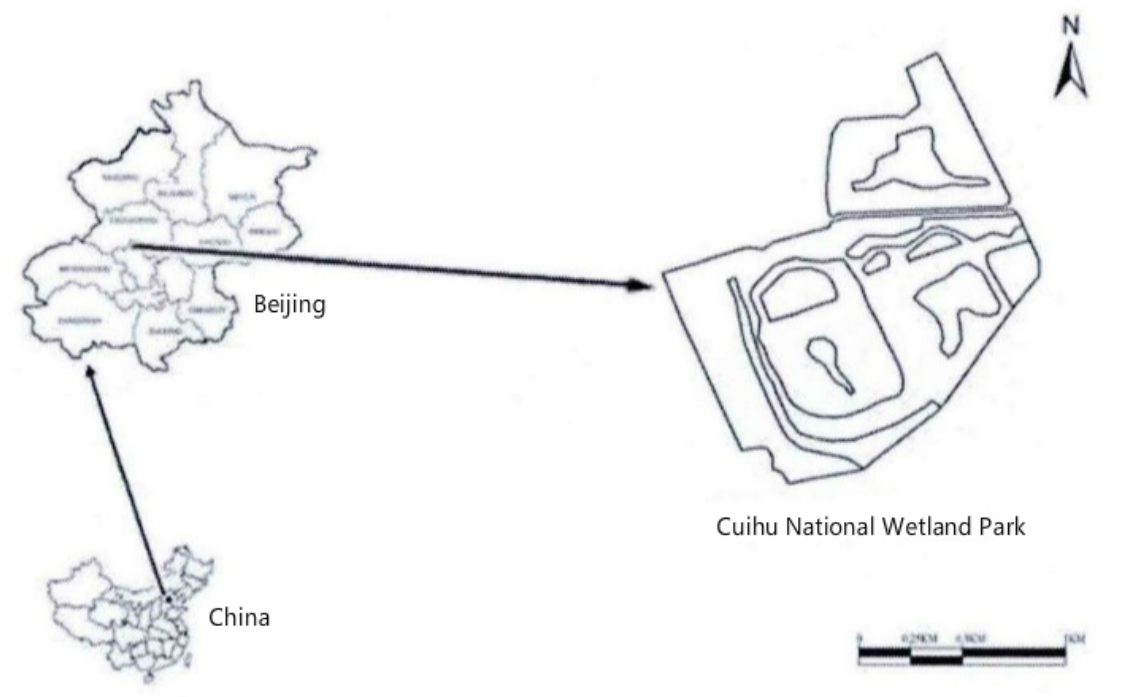

Fig. 1 Geographical location map of Cuihu wetland [14]

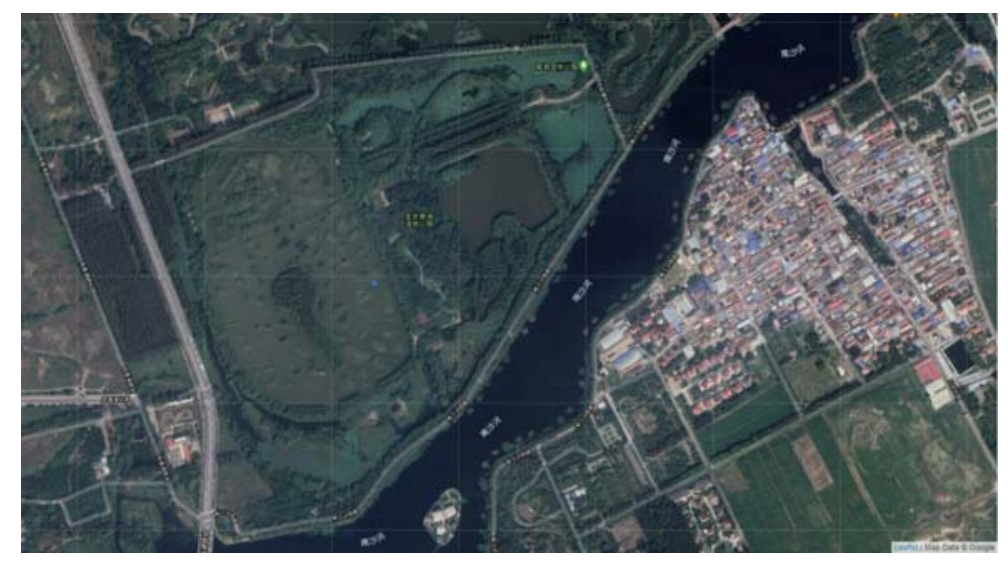

Fig. 2 Google satellite map of Cui Hu Wetland Park 


\section{Methods}

\subsection{Data sources}

\subsubsection{Bird data sources}

Traditional monitoring methods include long-term observation and repeated survey of sample sites. There were field-monitoring method, radar-monitoring method, wireless test and measurement method, satellitemonitoring method, Bird-ringing, stable isotope method and specimen method to study bird migration [15]. Scholars suggest that field-monitoring method should be used to regularly carry out on-site investigation and verification for key protected island birds [16].

According to the literature, the observation method adopted by the management and researchers of Cuihu wetland was the Spline method. Along the fixed survey route from 9:00 to 12:00 a.m. every day, the birds within $100 \mathrm{~m}$ around the transect were observed by telescope $(10 x)$, the bird species were judged by song characteristics, and the species and quantity were recorded.

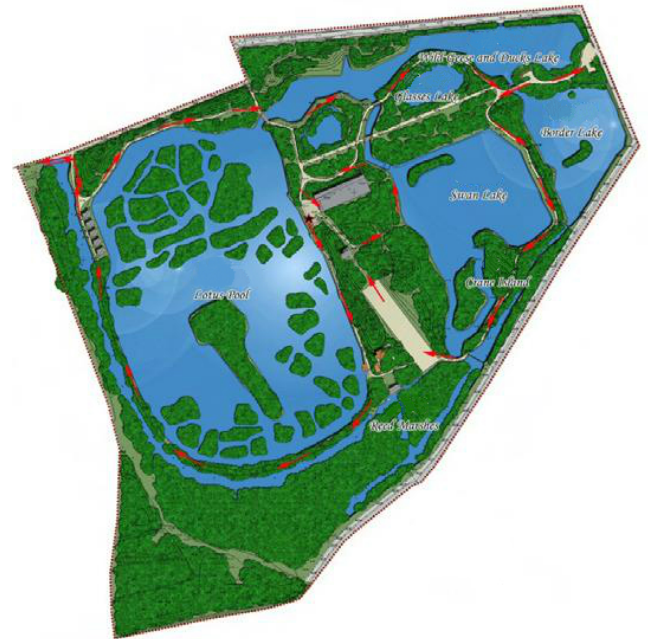

Fig. 3 Bird observation route in Cuihu wetland [17]
In this study, the field observation data (excluding feeding sites and breeding sites) of Cuihu wetland Management Department were obtained from the official website of Cuihu Wetland. The maximum observation value in the observation time interval, such as 99 mallard ducks, meaned that the observation peak value within one week is 99. The time span was from August 2015 to May 2018, and from November 14, 2013 to December 30,2014 . The data before November 2013, January to July 2015 and June 2018 are missing, and the existing data could support the statistical analysis [18].

\subsubsection{Climate data sources.}

The meteorological data were from the monthly average temperature and annual average temperature of Beijing area of China Meteorological Administration from 2013 to the first half of 2018 .

\subsection{Data analysis}

\subsubsection{Bird selection.}

Based on the collected data, it was found that there were Mallard, Goose, Green-winged teal, Ruddy Shelduck, Grey goose, Anas poecilorhyncha, Bar-headed goose, Little grebe, Mandarin Duck, Little Swan, Common merganser, Merganser with spotted head, Magpie duck, Crested catfish and Duck with upturned nose belonging to Geese and Ducks; Heron, Egret, Night Heron and Pond Heron belonging to egrets; Ring-necked pheasant, Moorhen, Chicken with chicken head, Fulica atra, Ruddy-breasted Crake, Rallus aquaticus, Grey-headed Lapwing, Black-winged stilt, Tringa ochropus, Mountain babbler, Alcedo atthis, Red tailed thrush, Turdus naumanni, Turdus merula, White-breasted Waterhen, Phalacrocorax carbo, Ceryle rudis, Common Tern, Ixobrychus sinensis and Motacilla alba, etc.

Table 1 Number and proportion of bird species recorded in autumn 2017 and winter 2018

\begin{tabular}{ccccccccc}
\hline Time & Start date & Cutoff date & Anatidae & Ardeidae & Total & $\begin{array}{c}\text { Percentage } \\
\text { of Anatidae }\end{array}$ & $\begin{array}{c}\text { Percentage } \\
\text { of Ardeidae }\end{array}$ & $\begin{array}{c}\text { Percentage } \\
\text { of others }\end{array}$ \\
\hline \hline & $2017 / 8 / 31$ & $2017 / 9 / 8$ & 964 & 379 & 1343 & $71.78 \%$ & $28.22 \%$ & $0.00 \%$ \\
& $2017 / 9 / 11$ & $2017 / 9 / 15$ & 1095 & 439 & 1539 & $71.15 \%$ & $28.53 \%$ & $0.32 \%$ \\
& $2017 / 9 / 18$ & $2017 / 9 / 22$ & 978 & 392 & 1375 & $71.13 \%$ & $28.51 \%$ & $0.36 \%$ \\
Autum & $2017 / 10 / 9$ & $2017 / 10 / 13$ & 971 & 357 & 1343 & $72.30 \%$ & $26.58 \%$ & $1.12 \%$ \\
2017 & $2017 / 10 / 16$ & $2017 / 10 / 20$ & 1325 & 332 & 1672 & $79.25 \%$ & $19.86 \%$ & $0.90 \%$ \\
& $2017 / 10 / 23$ & $2017 / 10 / 27$ & 1435 & 496 & 1947 & $73.70 \%$ & $25.48 \%$ & $0.82 \%$ \\
& $2017 / 10 / 30$ & $2017 / 11 / 3$ & 1148 & 373 & 1526 & $75.23 \%$ & $24.44 \%$ & $0.33 \%$ \\
& $2017 / 11 / 13$ & $2017 / 11 / 10$ & 1072 & 388 & 1466 & $73.12 \%$ & $26.47 \%$ & $0.41 \%$ \\
& $2017 / 11 / 20$ & $2017 / 11 / 1 / 24$ & 1290 & 446 & 1743 & $74.01 \%$ & $25.59 \%$ & $0.40 \%$
\end{tabular}




\begin{tabular}{ccccccccc} 
& $2017 / 11 / 27$ & $2017 / 12 / 1$ & 1067 & 337 & 1405 & $75.94 \%$ & $23.99 \%$ & $0.07 \%$ \\
\hline & $2018 / 3 / 1$ & $2018 / 3 / 7$ & 1031 & 400 & 1454 & $70.91 \%$ & $27.51 \%$ & $1.58 \%$ \\
& $2018 / 3 / 8$ & $2018 / 3 / 14$ & 789 & 300 & 1091 & $72.32 \%$ & $27.50 \%$ & $0.18 \%$ \\
& $2018 / 3 / 15$ & $2018 / 3 / 21$ & 784 & 309 & 1096 & $71.53 \%$ & $28.19 \%$ & $0.27 \%$ \\
\multirow{2}{*}{ Spring } & $2018 / 3 / 22$ & $2018 / 3 / 28$ & 803 & 313 & 1119 & $71.76 \%$ & $27.97 \%$ & $0.27 \%$ \\
& $2018 / 4 / 1$ & $2018 / 4 / 8$ & 458 & 501 & 959 & $47.76 \%$ & $52.24 \%$ & $0.00 \%$ \\
& $2018 / 4 / 9$ & $2018 / 4 / 15$ & 460 & 513 & 999 & $46.05 \%$ & $51.35 \%$ & $2.60 \%$ \\
& $2018 / 4 / 16$ & $2018 / 4 / 22$ & 498 & 535 & 1036 & $48.07 \%$ & $51.64 \%$ & $0.29 \%$ \\
& $2018 / 4 / 23$ & $2018 / 4 / 28$ & 495 & 530 & 1025 & $48.29 \%$ & $51.71 \%$ & $0.00 \%$ \\
\hline
\end{tabular}

From some observation records shown in Table 1, it could be clearly seen that the number of Geese and Ducks and Herons accounted for the vast majority of Cuihu wetland. Therefore, Geese and Ducks and Herons, which occupied the dominant number, were taken as the research objects of this study, and the correlation analysis of the dominant species was conducted based on the climate data. The number of other bird species was small, so it had no statistical significance.

\subsubsection{Statistical analysis}

Climate change might have an impact on the phenology of birds, mainly including the change of migration period and population number [19]. Some studies had shown that the climate of a nature reserve in Northeast China had a certain impact on the number of dominant species of banding birds in that year [20].

Therefore, the correlation between the monthly average of the number of Geese and Ducks and Herons in Cuihu wetland was studied in this study. Also, the observation data of birds in spring and autumn was compared with the climatic factors of the current season, the current season, the last year, the previous year, and the previous year. Among them, December of the last year, January and February of the year are regarded as the winter of the year, and March to May, June to August and September to November of the year as spring, summer and autumn of the year respectively. For example, the relationship between bird observation data and temperature in March to May in spring was studied. The correlation between the average number of birds observed in three months in spring and the average temperature of January to February and March to May of the year, March to December of the previous year, each quarter and the whole year of last year was analyzed.

Spss23.0 statistical software was used to analyze the impact of climate data on the number of Geese and Ducks and Herons in Cuihu wetland and the correlation analysis was conducted. Because the observed bird data and meteorological data were not all normal distribution, so Spearman correlation analysis method was used. Among them, $\mathrm{P}>0.05$ indicates no significant difference, $0.01<\mathrm{P} \leq 0.05$ indicated significant correlation, and $\mathrm{P} \leq$ 0.01 indicated extremely significant correlation.

\section{Results}

\subsection{The number of waterbirds was increasing}

According to the observation data, the number of Geese and Ducks and Herons in Cuihu wetland increased year by year from 2013 to 2018, as shown in Figure 4. The gap in the quantitative curve in the figure was the missing data, as described in Section 3.1

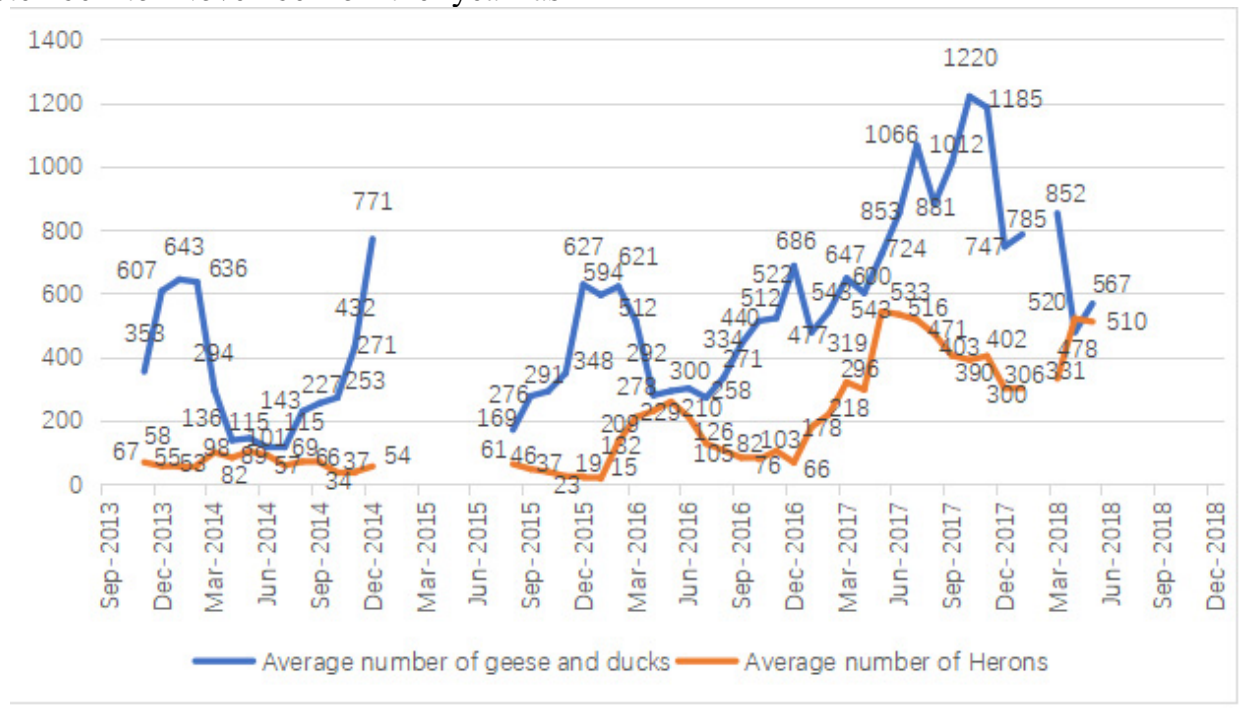

Fig. 4 Variation trend of observed quantity of Geese and Ducks and Herons from 2013 to 2018 


\subsection{The average monthly number of waterbirds was significantly correlated with temperature}

The correlation coefficient between the number of birds observed and the temperature in Cuihu wetland from 2013 to 2018 was shown in table 2. The average monthly number of Geese and Ducks was significantly correlated with the average monthly temperature, with a correlation coefficient of -0.379 , showing a negative correlation, that was, the higher average temperature of the month, the smaller number of Geese and Ducks observed. The average monthly number of Egrets was also significantly correlated with the average monthly temperature, with the correlation coefficient of 0.307 , that was, the higher average temperature of the month, the more Egrets were observed.

Table 2 Correlations between average monthly number of Geese and Ducks and Herons and average monthly temperature

\begin{tabular}{cc|c|c}
\hline & Spearman's rho & $\begin{array}{c}\text { Average monthly number } \\
\text { of Geese and Ducks }\end{array}$ & $\begin{array}{c}\text { Average monthly } \\
\text { number of Herons }\end{array}$ \\
\hline Average & Correlation Coefficient & $-.379^{* *}$ & $.307^{*}$ \\
monthly & Sig. (2-tailed) & .009 & .036 \\
temperature & $\mathrm{N}$ & 47 & 47 \\
\hline
\end{tabular}

**. Correlation is significant at the 0.01 level (2-tailed)

*. Correlation is significant at the 0.05 level (2-tailed).

\subsection{The number of waterbirds in spring and autumn was significantly correlated with the temperature in some areas in previous years}

\subsubsection{Correlation between the number of waterbirds and temperature in spring.}

The average number of birds observed in March, April and May over the years was summed up and averaged. The average monthly number of birds in spring was shown in table 3, in which the spring data of 2013 and 2015 were missing.

Table 3 Average monthly number of Geese, Ducks and Herons in spring 2014 to 2018

\begin{tabular}{ccc}
\hline Year & $\begin{array}{c}\text { Average monthly number of Geese } \\
\text { and Ducks in spring }\end{array}$ & $\begin{array}{c}\text { Average monthly number of } \\
\text { Herons in spring }\end{array}$ \\
\hline 2014 & 191 & 94 \\
2016 & 361 & 232 \\
2017 & 657 & 386 \\
2018 & 632 & 454 \\
\hline
\end{tabular}

The correlation analysis was made between the average number of birds in spring in 2014 and 20162018 with the average temperature of that year, the average temperature of last year, the average temperature of the current season, the average temperature of last spring, the average temperature of last summer, the average temperature of winter (December of last year and January to February of the same year), and the average temperature of March to December and January to May of last year respectively. The number of birds was significantly correlated with the average monthly temperature, but the average monthly number of birds in spring was not correlated with the average temperature of the year, season and month. Table 4 only listed a few groups of data with correlation, which showed that the average monthly number of Geese and Ducks in spring was significantly correlated with the average temperature in June and March of last year separately; while the average number of Herons in spring was significantly correlated with the average temperature in March of the same year, the average temperature of last spring, the average temperature of April and September of last year, and the average temperature of March of the same year was negatively correlated.

Table 4 Correlations between average monthly number of Geese, Ducks, Herons and temperature in spring

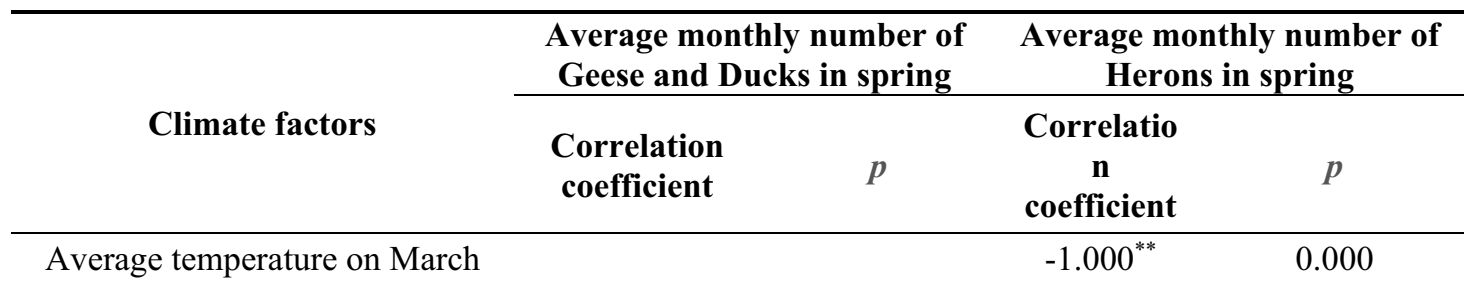


of the year

Average temperature of the year

Average temperature in spring in last year

Average temperature on March in last year

Average temperature on April in last year

Average temperature on June in last year

Average temperature on

September in last year

**. Correlation is significant at the 0.01 level (2-tailed)

$\begin{array}{ll}1.000^{* *} & 0.000 \\ 1.000^{* *} & 0.000\end{array}$

$1.000^{* *} \quad 0.000$

$1.000^{* *} \quad 0.000$

$1.000^{* *} \quad 0.000$

$$
1.000^{* *} \quad 0.000
$$

By adding and averaging the bird observation numbers in September, October and November over the years, the average monthly number of birds in autumn could be obtained, as shown in table 5, missing data in 2013 and 2018.

\subsubsection{Correlation between the number of waterbirds and temperature in autumn.}

Table 5 Average monthly number of Geese, Ducks and Herons in autumn 2014 to 2017

\begin{tabular}{ccc}
\hline Year & $\begin{array}{c}\text { Average monthly number of Geese } \\
\text { and Ducks in autumn }\end{array}$ & $\begin{array}{c}\text { Average monthly number of } \\
\text { Herons in autumn }\end{array}$ \\
\hline 2014 & 319 & 46 \\
2015 & 305 & 35 \\
2016 & 491 & 87 \\
2017 & 1139 & 398 \\
\hline
\end{tabular}

The correlation analysis was made between the average number of birds in autumn from 2014 to 2017 and the average temperature of that year, the average temperature of last year, the average temperature of autumn of that year, the average temperature of last autumn, the average temperature of winter of that year, the average temperature of spring, the average temperature of summer, the average temperature of September to December of last year and the average temperature of January to November of that year respectively. However, the average monthly number of birds in autumn was not correlated with the average temperature of all years, seasons and months. Table 6 only listed a few groups of data with correlation, which showed that the average monthly number of Geese and Ducks in autumn was significantly correlated with the average temperature in December of last year and the average temperature in October of that year; the average monthly number of Herons in autumn was also significantly correlated with the average temperature in December of last year and the average temperature in October of that year. There was a negative correlation between the numbers of Geese and Ducks and Herons with the temperature in October of that year, that is, the higher the temperature is, the smaller number of birds there will be.

Table 6 Correlation between average monthly number of Geese, Ducks and Herons and temperature in autumn

\begin{tabular}{|c|c|c|c|c|}
\hline \multirow{2}{*}{ Climate factors } & \multicolumn{2}{|c|}{$\begin{array}{l}\text { Average monthly number of } \\
\text { Geese and Ducks in autumn }\end{array}$} & \multicolumn{2}{|c|}{$\begin{array}{l}\text { Average monthly number of } \\
\text { Herons in autumn }\end{array}$} \\
\hline & $\begin{array}{c}\text { Correlation } \\
\text { coefficient }\end{array}$ & $p$ & $\begin{array}{c}\text { Correlation } \\
\text { coefficient }\end{array}$ & $p$ \\
\hline $\begin{array}{l}\text { Average temperature } \\
\text { on October of the year }\end{array}$ & $-1.000^{* *}$ & 0.000 & $-1.000^{* *}$ & 0.000 \\
\hline $\begin{array}{c}\text { Average temperature } \\
\text { on December in last } \\
\text { year }\end{array}$ & $1.000^{* *}$ & 0.000 & $1.000^{* *}$ & 0.000 \\
\hline
\end{tabular}

\section{Discussion}

The average monthly number of Geese and Ducks was negatively correlated with the corresponding average monthly temperature, while average the monthly number of Herons was positively correlated with the corresponding average monthly temperature. The number of Geese and Ducks reached the highest point in the whole year when the temperature dropped in late 
autumn and early winter, because it was the peak of flying southward for wild Geese and Ducks. Beijing, located on the East Asian Flyway, is their "gas station". And then the number of birds gradually decreases, reaching a low point when the temperature rosed in spring and lasted until the end of summer; when the temperature rosed in spring, the number of insects gradually increased, the food was rich, and the number of Herons reached the highest point of the whole year. Some of them would stay in the local area to breed, and some would continue to fly to the north. Then the number gradually decreased and reached the lowest point in the whole year by the end of autumn. The peak number of the two birds was opposite in spring and autumn.

The statistical analysis of the research data showed that not only the temperature of that year but also the temperature of the previous year has a significant impact on the number of Geese and Ducks and Herons. This conclusion provided a new direction and data support for the research and protection of wetland waterfowl. For example, Herons in spring were more affected by the temperature of last year than that of Geese and Ducks. The average number of Herons in spring was not only related to the average temperature in March of that year, but also significantly correlated with the average temperature of last year, spring of last year, April and September of last year separately. The average number of Geese, Ducks and Herons in autumn was significantly correlated with the average temperature in October and December of the previous year.

\section{Conclusion}

According to the statistics of Cuihu wetland, the number of birds in the wetland is increasing year by year. In a relatively short period of time, the increasing trend can't be determined to be associated with global warming. The main reason is due to the management of wetland park, which limit the number of tourists by appointment. This measure provides less human-disturbance habitat for animals in the park, and has a long-term ecological perspective and consciousness.

When formulating the protection and epidemic prevention programs and measures related to wetland waterfowl, the migration quantity of wetland birds can be predicted according to the records and laws of climate factors such as temperature in the same year and last year, so as to make adequate preparations.

To investigate the correlation between meteorological data and the number of bird migration needs the support of meteorological departments, and continuous and long-term observation and record of bird behavior. Rich and detailed data is conducive to accurate data processing and statistical analysis. This study is an exploration under the condition of limited public data. In the future, it is necessary for relevant institutions to establish a long-term and stable observation and recording mechanism for protection of wetland waterfowl, establish a professional team to record the wetland waterfowl phenological data, and do the environmental logging work, so as to provide the necessary basis for the establishment of better data model and further in-depth research.

This study explored the relationship between temperature and the number of migratory birds in wetland. In the future, more climate factors such as precipitation, wind speed, air pressure, even PM2.5 value, Arctic Oscillation and other climatic factors can be used for comparative analysis, so as to obtain a more comprehensive ecological cognition of wetland birds.

\section{Acknowledgments}

I would like to express my special thanks of gratitude to my teacher Yvonne as well as our teaching assistant, Yuting Qian, who helped me a lot in giving me different ideas in making this project unique. I came to know about so many new things and I am really thankful to them.

I would also like to thank my mother who helped me a lot in gathering different information and collecting data. Despite of her busy schedules, she guided me from time to time in making this project. The research can 't be satisfactorily completed without the support and guidance of my mother.

\section{References}

1. Liu, B. Impact of artificial lighting on migratory birds in Beijing and Tianjin[D]. Tianjin University, 2010.

2. Liu, H., Li, Y., Cao, X., et al. Research status, existing problems and development direction of wetland landscape in China[J]. Acta Geographica Sinica, 2009, 64 (11): 1394-1401.

3. IPCC 2007. Climate change 2007: the physical science basis. Cambridge, UK: Cambridge University Press.

4. Parmesan, C, Yohe, G. A globally coherent fingerprint of climate change impacts across natural systems[J]. Nature. 2003 Jan 2; 421(6918):37-42.

5. Saino, N., et al. Climate warming, ecological mismatch at arrival and population decline in migratory birds. Proc. Biol. Sci. 278, 835-842 (2011).

6. Chen, W., Dai, L., Xu, Z., Pan, Z., Dai, K. The threat of global warming to the status of Wuhan as a "transit station" of bird migration[J]. Sichuan Animal journal, 2008 (02): 248-250.

7. Genghini, M., Gellini, S., Gustin, M. Organic and integrated agriculture: the effects on bird communities in orchard farms in northern Italy[J]. Biodiversity and Conservation. 2006 (9)

8. Burger, J., Gochfeld, M. Metals and radionuclides in birds and eggs from Amchitka and Kiska Islands in the Bering Sea/Pacific Ocean ecosystem[J]. Environmental Monitoring and Assessment. 2007 (1)

9. Mao, Q., Yang, S., Jin, W., Jiao, L., Liu, L., Yan, Y., Yang, J. The process of Euglena sanguinea bloom in 
Beijing Cuihu National Wetland Park[J]. Lake Science, 2018,30 (02): 394-402.

10. Zhao, X., Cui, L., Li, W., Zhang, M., Shang, X., Zhang, Y. Environmental conditions for the occurrence of haemoglobus bloom in the Cuihu Wetland in Beijing[J]. Journal of water ecology, 2015,36 (02): 11-17.

11. Official website of Cuihu Wetland park, http://www.bjhd.gov.cn/chsd/sdxw/mtbd/201905/t2 0190513_4318175.htm.

12. Li, W., Cui, L., Zhao, X., Zhang, M., Wang, Y., Shang, X.. Habitat restoration and effect evaluation of Cuihu Wetland in Beijing[J]. Wetland science and management, 2013,9 (03): 17-21.

13. Official website of Cuihu Wetland park, http://www.bjhd.gov.cn/chsd/sdxw/mtbd/201905/t2 0190513_4318175.htm.

14. Zhang, R. Ecosystem health assessment of Cuihu wetland[D]. Beijing Forestry University, 2016.

15. Wilfried, T. Biodiversity: climate change and the ecologist[J]. Nature,2007,448(7153).

16. Yuan, L., Fu, Y., Yu, J., Li, F., Sun, Y. Review of bird migration and its research methods[J]. Biology teaching, 2017,42 (07): 8-10.

17. Zhang, Q., Li, X., Shang, X., Liu, Y., Wang, B., Zhang, F., Li, X. Current situation and Protection Countermeasures of bird resources in Cuihu Wetland in Beijing[J]. Wetland science and management, 2012,8 (02): 19-21.

18. Official website of Cuihu Wetland park, http://www.bjhd.gov.cn/chsd/sdyj/

19. Walther, G., Post, E., Convey, P., Menzel, A., Parmesan, C., Beebee, T.J.C., Fromentin J., HoeghGuldberg, O., Bairlein, F. Ecological responses to recent climate change[J]. Nature, 2002, 416(6879).

20. Zhang, X., Hao, Z.i, Xu, S., Wang, Y., Zhang, H. Correlation analysis of the number of dominant species and climatic factors in old fellow birds of Dalian[J]. Anhui Agricultural Sciences, 2020,48 (12): 90-94. 